\title{
Estrategias contra-sexuales del falo lesbiano: críticas a la teoría psicoanalítica lacaniana sobre la sexualidad femenina (Butler y Preciado)
}

\section{Contra-sexual strategies of the lesbian hallus: Critiques of lacanian psychoanalitic theory of femenine sexuality (Butler and Preciado)}

\author{
MAIDER TORNOS URZAINKI \\ Universidad de Barcelona
}

Recibido: 19/01/15 Aceptado: 05/06/15

\begin{abstract}
RESUMEN:
El psicoanálisis lacaniano, sustentado en la ideología del (hetero)patriarcado, afirma que la lógica hamletiana de ser y tener el falo es el juego que estructura la dicotomía de los dos sexos, reservando el segundo término de la dialéctica a la mujer, que permanece al abrigo de la figura del hombre. Por eso, desde las estrategias contra-sexuales del falo lesbiano, Butler y Preciado arremeten contra la dimensión simbólica del discurso hegemónico y recuperan los cuerpos (y deseos) deslegitimados por la moral económica del sistema capitalista, en contra de la lógica hamletiana del falo lacaniano.
\end{abstract}

\section{PALABRAS CLAVE:}

DIALÉCTICA HAMLETIANA DEL FALO LACANIANO, FALO LESBIANO, PLASTICIDAD DE LO IMAGINARIO, DILDO, ESTRATEGIAS CONTRA-SEXUALES. 
ABSTRACT:

Lacanian psychoanalysis, based on (hetero)patriarchal ideology, claims that the Hamletian logic of being and having the phallus is what structures the dichotomy of the two sexes, reserving the second term of the dialectic to woman, who remains sheltered by the figure of man. Conversely, from the contra-sexual strategies of the lesbian phallus, Butler and Preciado charge against the symbolic dimension of a hegemonic discourse and recover the bodies (and desires), which are delegitimized by capitalist morality, against the Hamletian logic of the Lacanian phallus. KEYWORDS:

HAMLETIAN DIALECTIC OF LACANIAN PHALLUS, LESBIAN PHALLUS, PLASTICITY OF THE IMAGINARY, DILDO, CONTRA-SEXUAL STRATEGIES

Mi mujer con el sexo de alga y de bombones antiguos - Mi mujer con el sexo de espejo.

André Breton

HistóRicAmente, de acuerdo con la lógica hegemónica del (hetero)patriarcado, el cuerpo de la mujer es concebido como un espejo, al servicio de la construcción de la morfología masculina. Sin forma, privado de determinación ontológica, el cuerpo de la mujer es un recipiente, que contiene las proyecciones del otro sexo: el único cuerpo sexuado. La mujer-su cuerpo, su sexo-es el reverso negativo, el lugar de la falta, la topología de la envidia, en donde el sexo masculino encuentra la autorrepresentación de su propio cuerpo, en un juego dialéctico que implica exclusión y violencia. Al fin y al cabo, dice Irigaray, la sexualidad femenina «siempre ha sido pensada a partir de parámetros masculinos» (1977, p. 17), obligando a la mujer a convertirse en el soporte especular que sustenta la figura hegemónica del hombre. Así, la mujer queda relegada a la posición de la alteridad, mientras que el hombre ocupa el lugar del sujeto, estableciendo una jerarquía que recorre -de manera estructural- la configuración de la sociedad capitalista.

Desde mediados del siglo XX, la teoría freudo-lacaniana se acerca a la figura de lo femenino, con el fin de explicar -a través de la herida que provoca la ausencia (o la diferencia) - las particularidades que esconde su cuerpo, siempre enigmático y misterioso. Para el psicoanálisis lacaniano, sustentado en la ideología del (hetero)patriarcado, la lucha hamletiana de ser y tener el falo se convierte en el juego que estructura la dicotomía de los dos sexos, reservando el segundo término de la dialéctica a la mujer, que permanece -perdida y olvidada - al abrigo de la figura del hombre. Por eso, desde la teoría del falo 
lesbiano, este trabajo recupera los cuerpos (y deseos) deslegitimados por la moral económica del sistema capitalista, en contra de la lógica hamletiana del falo lacaniano, con el fin de visibilizar los cuerpos que quedan escondidos detrás del orden simbólico del discurso, cuando el significante trascendental del Nombre-del-Padre impone su ley y su castigo. En el límite, desde la impropiedad lingüística (¿la catacresis?), el cuerpo de la mujer lesbiana -gracias a la plasticidad del falo- se convierte en un arma política, que destapa la violencia estructural con la que se marcan (todos) los cuerpos, apelando a una dimensión que queda más allá de la sexualidad (hetero)normativa del sistema capitalista.

\section{LA DIALÉCTICA HAMLETIANA DEL FALO LACANIANO}

¡Eh! ¿Qué es eso? Exo. ¿Sabes qué es eso? eso, exo, eso es un sexo. ¿Sabes qué es? eso exo es, sexo es, este exceso. El sexo fue el primer exceso; causó y causa todos los excesos... ¿Qué tengo? ¿qué tengo? quequé tengo. ¿Qué tengo que es? quequé es esto. ¿Qué que eres? Quéquete. ¿Qué quieres tú? quéque quieres. ¿Qué tengo que es esto que tengo en? ¿Qué tengo que sexo tengo tiene? ¿quesquesex?

Jean-Pierre Brisset

A lo largo de su carrera, con respecto a la sexualidad femenina, Freud trata de responder a la eterna pregunta: ¿Qué quiere una mujer?, pero con poco éxito. En «Tres ensayos sobre teoría sexual» (1905), Freud analiza de manera pormenorizada la sexualidad humana y, a partir del modelo de la biología darwinista, propone la teoría del monismo sexual, en donde la libido es de esencia masculina. Posteriormente, en «La organización genital infantil (una interpretación en la teoría de la sexualidad)» (1923), Freud instituye la primacía del falo y afirma lo siguiente: «El carácter principal de esa organización genital infantil es, al mismo tiempo, su diferencia respecto de la organización genital, definitiva del adulto. Reside en que, para ambos sexos, sólo desempeña un papel un genital, el masculino. Por tanto, no hay un primado genital, sino un primado del falo» (1923, p. 146). Según explica Freud, después de la fase oral y la fase anal, aparece la fase fálica, que se caracteriza por la unificación de las pulsiones, bajo el primado de los órganos genitales. No obstante, a diferencia de la organización genital puberal, el niño y la niña - en la fase fáli- 
ca- sólo reconocen un órgano genital: el masculino. ${ }^{1}$ Así, en estos momentos, la oposición de los dos sexos equivale al par antitético de fálico/castrado y no al de masculino/femenino, que aparece -posteriormente-con el desarrollo de la pubertad. ${ }^{2}$ Por lo tanto, la sexualidad -al quedar construida en relación a la marca sexual masculina (desde la posición dicotómica de fálico/castrado) origina distintas maneras de enfrentarse con el complejo de Edipo, no sólo por las diferencias anatómicas evidentes, sino por las fantasías que suscitan estas diferencias: en el niño, el miedo a la castración; en la niña, la envidia del pene. A partir de esta teoría, Freud afirma lo siguiente: «lo masculino reúne el sujeto, la actividad y la posesión del pene; lo femenino, el objeto y la pasividad» (1923, p. 149). Para Freud, la envidia del pene -en las mujeres- y el complejo de castración -en los hombres- son las fantasías que delimitan y condicionan la sexualidad del ser humano a lo largo de toda su vida, convirtiéndose en los cimientos que sustentan la lógica opositiva y jerárquica de los dos sexos, en una sociedad capitalista y (hetero)patriarcal, cuya finalidad es garantizar la conservación de la especie humana.

1 La significación de la fase fálica, especialmente en la niña, ha dado lugar a muchas discusiones en la historia del psicoanálisis. Autores como Karen Horney, Melanie Klein o Ernst Jones hablan de un conocimiento intuitivo y primario de la cavidad vaginal y se ven inducidos a considerar la fase fálica sólo como una formación secundaria de tipo defensivo. No creen, por lo tanto, que la niña ignore la vagina (y la sustituya por el clítoris), sino que deniega la vagina. En la misma línea, Irigaray afirma lo siguiente: «Esa denegación de la vagina por parte de la chiquilla se justificaría por el hecho de que es, a su vez, temido. La comparación del pene de un hombre adulto con la exigüidad de la vagina infantil, la visión de las menstruaciones, o incluso eventuales y dolorosos desgarros del himen durante las exploraciones manuales han podido, en efecto, instigar en la chiquilla el temor a tener una vagina, y a negar lo que ella sabe de su existencia» (1977, p. 23).

2 Para muchos teóricos, la fase fálica de Freud proporciona el retorno a la androginia, que permite superar el horror que provoca el corte de los dos sexos, a través de la indiferenciación de las marcas sexuales, ya que el juego no se sostiene en la dualidad masculino/femenino, sino en la dualidad fálico/castrado. En este sentido, por ejemplo, Brown comenta: «la diferenciación sexual de la libido adulta (...) es una pérdida de la integridad sexual. Por eso, el hecho de la diferenciación sexual se mira con horror. En cada sexo, dice Freud, hay la actitud que pertenece al sexo opuesto que sucumbe a la represión. En cada sexo el inconsciente no acepta la represión sino que quiere recuperar la bisexualidad de la infancia. (...) En el nivel más profundo el ideal andrógino o hermafrodita del inconsciente refleja la aspiración del cuerpo humano de superar los dualismos que son sus neurosis» (1959, p. 153). Sin embargo, a pesar de estas hipótesis, la fase fálica no se puede identificar con la androginia, porque la marca femenina del cuerpo sexuado no es reconocida en ningún momento, ya que sólo existe el órgano genital masculino. 
Años más tarde, en el Seminario XX: Aún (1972-1973), Lacan cifra la economía sexual en la dicotomía freudiana de la fase fálica y, en la ecuación dialéctica de ser y tener el falo, construye una sexualidad que funciona por oposiciones binarias, a partir de la sujeción (y la subjetivación) que provoca la dimensión simbólica del discurso. Ahora, el orden del lenguaje y, concretamente, la marca que imprime el significante fálico del Nombre-del-Padre revela la estructura discursiva con la que se graban los cuerpos, a través de una lógica (hetero)normativa, acorde con el sistema productivo y (re)productivo de la economía capitalista. El falo, para Lacan,

No es (...) como tal un objeto (parcial, interno, bueno, malo, etc.) en la medida en que ese término tiende a apreciar la realidad interesada en una relación. Menos aún es el órgano, pene o clítoris, que simboliza. (...) el falo es un significante, un significante cuya función, en la economía intrasubjetiva del análisis, levanta tal vez el velo de la que tenía en los misterios. Pues es el significante destinado a designar en su conjunto los efectos del significado, en cuanto el significante los condiciona por su presencia de significante. Examinemos pues los efectos de esa presencia. Son en primer lugar los de una desviación de las necesidades del hombre por el hecho de que habla, en el sentido de que en la medida en que sus necesidades están sujetas a la demanda, retornan alienadas a él (1958, p. 657).

De acuerdo con la teoría lacaniana, la envidia del pene y la angustia de castración motivan la creación del falo: un registro imaginario, que-frente a la carencia del objeto real que estructura la diferencia- permite recubrir la falta, a través de una serie de proyecciones fantasmáticas que tratan de alcanzar la completud del ser del sujeto, en un proceso de desplazamiento interminable que no termina (nunca) de terminar. Así, desde la dimensión imaginaria, el falo se convierte en el significante simbólico, que -con la ayuda del Nombre -del-Padre- ordena el juego dialéctico del complejo de Edipo y codifica los registros del deseo. Influenciado por el mito freudiano de la horda primitiva, Lacan afirma que la figura del padre es el soporte del fantasma de un goce absoluto, ya que su posición trascendente le permite ejercer la castración, pero sin padecer ese castigo en la dimensión de su propio cuerpo: es el hommoinzin (homme moins un), que -en contra de las teorías que identifican el falo con una fase o con un simple objeto parcial- hace referencia a la trascendencia del significante fálico que impone la castración, configurando la dimensión de la falta que -en última instancia- organiza el campo de la sexualidad. De esta manera, explica Lacan, se instaura una dialéctica hamletiana -sustentada en una lógica distributiva-, que obliga al sujeto a adoptar un rol determinado, con el que enfrentarse a la experiencia de la pérdida: ' $O$ ser el falo $o$ tener el falo' es la disyuntiva que se le presenta al sujeto en estos momentos, ya que no puede ser -al mismo tiempo- el objeto que colma la carencia y el sujeto que 
sufre esa carencia. Así, de acuerdo con esta tragedia de corte dialéctico, está el sujeto que decide ser el falo, para colmar la falta en el Otro, al convertirse en su objeto de deseo: «si el deseo de la madre es el falo, el niño quiere ser el falo para satisfacerlo» (Lacan 1958, p. 660). De esta manera, nace el amor: una interpretación del deseo del Otro, que obliga al sujeto a adoptar la posición de objeto de deseo, para llenar el vacío que define el ser del Otro. En este sentido, comenta Zizek, «la respuesta del amor es 'Yo soy lo que a ti te falta; con mi devoción a ti, con mi sacrificio a ti, te llenaré, te completaré'» (1989, p. 160). Ahora, al convertirse en un objeto de deseo, el sujeto intenta contrarrestar la carencia que invade al Otro, ofreciéndole aquello que le falta para llegar a ser completo y, a su vez, trata de aliviar su propia carencia, renunciando a ocupar la posición de sujeto de deseo, que -al final- es la experiencia que desgarra la completud del ser. Éste es, dice Zizek, el engaño del amor: creer «que esta superposición de dos faltas anula la falta como en una completud mutua» (1989, p. 160). Por otra parte, está el sujeto que quiere tener el falo y, por eso, rechaza convertirse en el objeto de deseo del Otro y adopta una posición de sujeto deseante, que debe pasar - previamente-por una aceptación de la afánisis que rompe su ser y lo separa de sí mismo. Este sujeto que ya no quiere ser el falo, sino que quiere tenerlo se desplaza de manera metonímica por distintos objetos parciales, con los que trata de calmar el vacío que introduce el efecto del significante. Así, de acuerdo con la teoría lacaniana, la dialéctica hamletiana de ser y tener el falo -impuesta por la ley de la castración simbólica-divide el campo de la sexualidad en dos mitades antagónicas, que están abocadas a no entenderse nunca. ${ }^{3}$

Sin embargo, para Lacan, la estrategia dialéctica que utiliza el significante fálico, para cubrir el horror que produce la falta (en lo real), acaba instalándose de manera determinada en el cuerpo del hombre y en el cuerpo de la mujer. A

3 A lo largo de los años, Lacan insiste en el carácter unitario del significante fálico, cuya indivisibilidad impide abrirse a la presencia del otro, para acoger la estructura dual que define toda relación sexual. Por eso -porque Hay Uno y, por lo tanto, no hay dos-, Lacan llega a la conclusión de que no hay relación sexual. Al fin y al cabo, con la ley de la castración simbólica -impuesta por el significante fálico-, se produce un corte que instituye la diferencia sexual en los cuerpos, condenados -a partir de ese momento- a no entenderse nunca. La relación sexual, a causa de la herida que provoca la violencia del orden simbólico, no puede recibir el ser del otro y acaba recluyéndose en la soledad que proporciona un goce autístico y autorreferencial -que sólo goza de sí mismo-, haciendo que la relación sexual desemboque en la frustración. De esta manera, para el psicoanálisis lacaniano, la relación sexual no es un proceso teleológico que culmina con la fusión y el reconocimiento mutuo, sino un proceso abierto y constante, que transcurre en la distancia intermedia que (a la vez) acerca y separa los cuerpos. Por ese motivo, para poder suplir la soledad, el orden imaginario crea el amor. 
partir de aquí, Lacan reserva el registro del tener al hombre, que se convierte en un sujeto deseante, sustentado en la búsqueda metonímica del objeto a que le falta, para llegar a ser completo; $y$, a su vez, Lacan asigna la posición del ser a la mujer que, como objeto deseado, repliega (¿esconde?) su propio deseo en el deseo del hombre. De esta manera, a través de la teoría del significante fálico, Lacan se adentra en los dominios de la sexualidad (hetero)normativa, basada en la distinción binaria de los dos sexos, en donde la mujer -desde el registro del ser- ocupa la posición negativa, convirtiéndose en el objeto de deseo que calma el vacío del hombre. Su cuerpo (sin forma) es el espejo que sustenta la ontología masculina, en una sociedad (hetero)patriarcal que funciona por oposiciones binarias, en donde el reconocimiento de la figura del otro (diferente) conlleva su exclusión y su rechazo.

\section{LA PLASTICIDAD IMAGINARIA DEL FALO}

Lesbiana es el único concepto que conozco que está más allá de las categorías de sexo (mujer y hombre), pues el sujeto designado (lesbiana) no es una mujer ni económicamente, ni políticamente, ni ideológicamente.

Monique Wittig

En Cuerpos que importan. Sobre los límites materiales y discursivos del sexo (1993), Judith Butler asume la ecuación hamletiana del falo lacaniano, con el fin de subvertir la sexualidad heteronormativa que se instituye con la violencia que imprime el orden simbólico del lenguaje, cuando la ley del Nombre-delPadre golpea el cuerpo y emerge la dimensión del deseo. Así, a partir de una lectura atenta de la teoría lacaniana sobre el estadio del espejo, Butler apela a la dimensión plástica del orden imaginario y plantea la teoría del falo lesbiano, desarticulando la dicotomía discriminatoria del ser y el tener con la que se graban los cuerpos, al destruir la posición trascendental que ocupa el falo lacaniano en la cadena estructural de significantes. De esta manera, a través de un juego reiterado de identificaciones, Butler convierte el falo lacaniano en un objeto parcial -sometido al juego infinito de sustituciones metonímicas-, hecho que le permite cuestionar los esquemas sexuales esencialistas, visibilizando los cuerpos (y deseos) que se mantienen al margen del sistema (hetero) normativo del patriarcado.

En «El estadio del espejo como formador de la función del yo [je] tal como se nos revela en la experiencia psicoanalítica» (1949), Lacan explica la transformación que se produce en el sujeto, cuando - entre los seis y los dieciocho 
meses de vida- se pone delante del espejo y asume la imagen que se refleja en el cristal. Para Lacan, la identificación con la imagen que nos devuelve el espejo tiene efectos formativos sobre el organismo y permite establecer -a través de la función de la Imago - una relación del organismo (Innenwelt) con la realidad (Umwelt). En este sentido, según explica Lacan, la insuficiencia orgánica del sujeto -en sus primeros años de vida-marca su desamparo original, que queda reflejado en la impotencia y la descordinación motriz del sujeto, debido a la inmadurez biológica de un cuerpo anatómicamente incompleto. Sin embargo, su prematuración natal fisiológica es superada gracias al estadio del espejo, a través de la identificación del sujeto con la imagen visual (Gestalt) de su propio cuerpo en el espejo. Es, en ese momento, cuando el infans «anticipa en el plano mental la conquista de la unidad funcional de su propio cuerpo, todavía inacabado en ese momento en el plano de la motricidad voluntaria» (Lacan 1948, p. 117). Así, a través de la identificación con la representación imaginaria, la instancia del espejo construye «una forma que llamaremos ortopédica de su totalidad» (Lacan 1949, p. 103). Esta experiencia primordial-que posibilita la reconstrucción del cuerpo fragmentado, gracias a una forma imaginaria- se encuentra en la base del carácter imaginario del yo [moi], constituido como yo-ideal: origen del narcisismo lacaniano. Así, como el nivel biológico del ser humano es insuficiente y lacunario, el estadio del espejo compensa las carencias instintivas del hombre y, a través de la identificación imaginaria con ese doble que se proyecta en el espejo, el sujeto puede llegar a dominar la anarquía de las pulsiones que atraviesan (y desestructuran) su cuerpo. Influenciado por la Fenomenología del espíritu (1807), a través de los seminarios impartidos por Kojève en la École des Hautes Études en París (1933-1939), Lacan llega a la conclusión de que la identidad del sujeto sólo se construye a través del pasaje, en un proceso de mediación con el ser del otro: «es preciso, por lo menos, ser dos para ser humano», decía Kojève (1937-1938, p. 183). Por lo tanto, la constitución de la subjetividad se configura desde una exterioridad -a través de la imagen del otro- y no sobre un poder de síntesis de la conciencia. Así, Lacan pone al descubierto la estructura en espejo del yo y destruye la noción de un yo autónomo: «el estadio del espejo nos opone a toda filosofía derivada directamente del cogito», comenta Lacan (1949, p. 99). De esta manera, se construye el principio dialéctico que domina el estadio del espejo, que «sitúa la instancia del yo, aun desde antes de su determinación social, en una línea de ficción, irreductible para siempre por el individuo solo» (Lacan 1949, p. 100). $\mathrm{Y}$, a partir de la confrontación dialéctica con la imagen, Lacan arremete contra la teoría freudiana del narcisismo primario - configurado en la inmediatez autorreferencial del yo que, para Freud, es el gran reservorio de la libido-y apela a la construcción dialéctica del ser del sujeto, en relación a una imagen exterior que lo expropia de sí mismo. Así, para Lacan, el narcisismo ya no supone una 
originaria investidura libidinal del yo y, por lo tanto, no existe antes del juego de la identificación, sino que depende de la mediación cultural de la imagen, que siempre queda más allá del determinismo natural del cuerpo biológico.

Heredera de la teoría lacaniana sobre el estadio del espejo, Butler afirma que la constitución de la identidad del sujeto se forma de manera inestable y momentánea, desde la exterioridad incómoda de la Imago, a través de una serie de procesos de identificación, que -al margen del sustrato biológico de la anatomía- revelan una verdad hecha a base de máscaras y ficciones. Para Butler, por lo tanto, los procesos de identificación «son la sedimentación del nosotros en la constitución de cualquier yo, la presencia estructurante de la alteridad en la formulación misma del yo» (2002, p. 159), hecho que indica el carácter excéntrico del sujeto, que está obligado a vivir en la exterioridad de sí mismo. Además, como el yo-corporal producido a través del proceso de identificación no está miméticamente relacionado con el cuerpo biológico, Butler considera que es posible crear un esquema imaginario alternativo, que tenga la capacidad de abrir nuevos espacios de placer, en contra de la disposición (hetero) normativa del deseo patriarcal y hegemónico. En este sentido, explica Butler, el yo-ideal que construye el proceso del estadio del espejo autoriza la disrupción entre el cuerpo-anatómico y el cuerpo-ideal, desestructurando la relación falo/ pene que -hasta ahora- ha sustentado la lógica (hetero)normativa del sistema capitalista. A partir de aquí, con el fin de subvertir el contrato heterosexual, Butler reivindica la plasticidad del falo lesbiano, demostrando que la parodia, la fantasía y el imaginario tienen la capacidad de transgredir el sistema de la norma, en un proceso marcadamente político y revolucionario, que trabaja para dar voz a los cuerpos (y deseos) excluidos. Así, comenta Butler,

Lo que debemos preguntarnos, por supuesto, es por qué se da por descontado que el falo requiere de esa parte particular del cuerpo para simbolizar y por qué no puede operar simbolizando otras partes del cuerpo. La viabilidad del falo lesbiano depende de este desplazamiento. $\mathrm{O}$, para decirlo más precisamente, el carácter desplazable del falo, su capacidad de simbolizar en relación con otras partes del cuerpo o con otras cosas semejantes al cuerpo, abre la posibilidad de introducir la noción del falo lesbiano, una formulación que de otro modo sería contradictoria. Y aquí deberíamos dejar en claro que el falo lesbiano combina el orden de tener el falo y el de ser el falo (1993, p. 133).

Ahora, de acuerdo con la estrategia del falo lesbiano, las disposiciones (¿incompatibles?) del ser y el tener se confunden, rompiendo con el principio de no contradicción de la lógica aristotélica, hecho que permite cuestionar las figuras centrales de poder, a través de una erotización alternativa del cuerpo. De esta manera, al combinar la dimensión del tener y la dimensión del ser, la lesbiana-desde una posición inadecuada-cuestiona la morfología masculina 
y la morfología femenina, en una resignificación del falo lacaniano, que funda un deseo insubordinado y transgresor. Así, desde una mímesis crítica, el falo lesbiano pone en tela de juicio la lógica hamletiana del psicoanálisis, ya que consigue romper -gracias a la perversión metonímica del significante- la equivalencia perfecta del falo/pene en el esquema lacaniano, en un juego de negociaciones perpetuas entre la norma y la desviación de la norma. Para Butler, por lo tanto, el significante fálico puede llegar a significar algo más que la posición estructural que marca el significado del pene, ya que su desplazamiento reiterado desarticula el point de capiton lacaniano -en donde el falo y el pene se equiparan-, a través de una cadena infinita que no hace más que subvertir la lógica (hetero)normativa del sistema capitalista. En este sentido, dice Butler, es importante considerar que «el hecho de tener el falo puede simbolizarse mediante un brazo, una lengua, una mano (o dos), una rodilla, un muslo, un hueso pelviano, una multitud de cosas semejantes al cuerpo deliberadamente instrumentalizadas» (1993, p. 139). Así, producto de esta combinatoria lesbiana, Butler afirma el desplazamiento metonímico de la función del falo, que -sin poder conservar (por más tiempo) su posición trascendental en la cadena de significantes- se traslada desde el pene hacia otras regiones corporales, diversificando la geografía del deseo. De esta manera, después de adoptar las enseñanzas lacanianas, Butler reivindica el falo lesbiano (y no el pene lesbiano), porque su finalidad no es construir nuevos espacios corporales, sino crear -a través de las posibilidades performativas que ofrece el imaginario-nuevas estrategias de empoderamiento, que permitan desarticular la hegemonía del orden simbólico, para dar cabida a nuevos cuerpos y nuevos deseos.

Sin embargo, gracias a la teoría del falo lesbiano, Butler no sólo reclama el deseo polimorfo de la lesbiana, sino que su intención es visibilizar todas las prácticas sexuales que se constituyen más allá del sistema social de la norma, cuando los juegos de identificación -en contra del esquema lacaniano- producen un imaginario que desarticula el (¿falso?) determinismo biológico de la anatomía. Así, si el discurso patriarcal y (hetero)normativo se constituye desde la exclusión de la diferencia, la finalidad de Butler es desestabilizar el orden simbólico del lenguaje, para poder volver a reconsiderar el conjunto heterogéneo de las sexualidades periféricas:

hombres que desean ser el falo para otros hombres, [...] mujeres que desean tener el falo para otras mujeres, [...] mujeres que desean ser el falo para otras mujeres, [...] hombres que desean tener y ser el falo para otros hombres, en un escenario en el que el falo se transfiere no solamente entre las modalidades de ser y tener, sino además entre los individuos que se relacionan entre sí dentro de un circuito volátil de intercambio, hombre que desea ser el falo para una mujer que lo tiene, mujeres que desean tenerlo para un hombre que lo es (1993, p. 156). 
Al final, el falo lesbiano revela un tipo de deseo excesivo, abyecto y perverso, condenado por la lógica (hetero)normativa del sistema capitalista, que es incapaz de aceptar las sexualidades que atentan contra la lógica económica del capitalismo y desestabilizan la homeostasis del sistema social. Sin embargo, a pesar de que la lesbiana arremete contra la violencia simbólica y descubre un deseo ilegítimo, Butler afirma que sus prácticas no pueden derrocar la lógica del falo: «la sexualidad lesbiana está tan construida como cualquier otra forma de sexualidad dentro de los regímenes sexuales contemporáneos» (1993, p. 135). Por eso, al asumir la dimensión del falo lesbiano, Butler critica el materialismo de Monique Wittig, porque no comparte esa búsqueda desesperada de un estado natural -anterior a la dimensión simbólica del discurso-, en donde el sexo puede desprenderse (por fin) del control que ejercen las estructuras de poder ${ }^{4}$. Así, influenciada por la positividad del poder foucaultiano (potentia vs. potestas), Butler llega a la conclusión de que la estrategia de la lesbiana no consiste en plantear una relación sexual liberada del poder del falo, sino en demostrar que - desde la parodia y la mascarada - el poder puede llegar a producir (también) la dimensión de lo prohibido, en un proceso paradójico que implica la desautorización de su propia eficacia. Por eso, explica Butler, «Lo interesante no es si el falo persiste en la sexualidad lesbiana como un principio estructurante, sino cómo persiste» (1993, p. 135). En este caso, a través de un proceso de resignificación constante, el falo lesbiano posibilita la variabilidad y el cambio de las categorías sexuales -al margen de los esquemas esencialistas-, demostrando que los conceptos de hombre y mujer no son eternos y naturales, sino que son ficciones políticas, creadas con el fin de perpetuar la economía productiva y (re) productiva del (hetero)patriarcado. Hasta ahora, si bien para el psicoanálisis el cuestionamiento de la ley del significante fálico se acompaña de la fantasía de la disolución psicótica, Butler se pregunta si esa patologización de la rebeldía no es un (¿sutil?) mecanismo del sistema capitalista, cuya finalidad es castigar

4 Butler, concretamente, dice: «Mientras que Wittig prevé, de forma obvia, que el lesbianismo es un repudio total de la heterosexualidad, yo afirmaría que incluso ese repudio es un compromiso y, en definitiva, una dependencia total de los mismos términos que el lesbianismo pretende trascender». Y sigue: «su propósito [de Wittig] es explicar la idea de un cuerpo natural como una construcción y proponer una serie de estrategias deconstructivas/reconstructivas para configurar cuerpos que refuten el poder de la heterosexualidad. El contorno y la forma misma de los cuerpos, su principio unificador, sus partes compuestas, siempre están figurados por un lenguaje imbuido de intereses políticos. Para Wittig, el reto político consiste en adueñarse del lenguaje como el medio de representación y producción, tratarlo como un instrumento que reiteradamente construye el campo de los cuerpos y que debería utilizarse para deconstruir y reconstruir los cuerpos fuera de las categorías represoras del sexo» (1999, p. 146 y 248). 
las prácticas sexuales que no se someten a las normas del (hetero)patriarcado. Así, según explica Butler, el falo lesbiano se constituye a través de un proceso performativo que negocia las normas establecidas, cuestionando la dimensión hegemónica del discurso y creando una serie de prácticas de intervención y resignificación política, gracias a la fuerza desestabilizadora que encierra el orden de lo imaginario. En definitiva, para Butler, las posiciones sexuales no son localidades fijas, sino que son prácticas citacionales -instituidas dentro del terreno jurídico-, que hacen que la encarnación del sexo sólo sea una manera determinada de convocar la ley.

III. EN EL PRINCIPIO ERA EL DILDO...

Not gay as in happy; but queer as in fuck you. Wingnut Anarchist Collective.

En El manifiesto contrasexual (2000), influenciado por la teoría del falo lesbiano, Preciado instituye la era de la dildotectónica, con el fin de desnaturalizar la diferencia sexual de los cuerpos, a través de un suplemento prostético que produce aquello que (supuestamente) debe completar. No obstante, a pesar de su interés por la plasticidad y la mutabilidad del falo lesbiano, Preciado critica que las propuestas butlerianas -demasiado condicionadas por la ortodoxia del psicoanálisis lacaniano- descuidan la materialidad del cuerpo, apelando a la trascendencia del orden imaginario, como sustrato de la lucha contra-sexual y revolucionaria. En cambio, Preciado se preocupa por los efectos de inscripción que los juegos de identificación producen en el cuerpo y, por ese motivo, reivindica el soporte material del dildo, porque considera que la insurrección contra-sexual debe hacerse con el cuerpo (y no sólo con el imaginario). Así, en contra de la centralidad de la dimensión imaginaria en la teoría butleriana, Preciado - del mismo modo que Foucault- trata de pensar las diferentes prácticas sexuales: esas maneras concretas de hacer sexo, que -en última instanciaconstruyen la arquitectura del cuerpo. En este sentido, a través del carácter suplementario del dildo, Preciado reclama una sociedad contra-sexual, en una deconstrucción sistemática del predeterminismo biológico de la anatomía, con el fin de recuperar la contraproductividad de un cuerpo abyecto e insumiso. De esta manera, desde los presupuestos de la teoría queer y el (trans)feminismo, Preciado trata de subvertir el campo epistémico que instituye el dispositivo de la sexualidad, porque su intención es demostrar que la verdad sobre el sexo -al margen de la naturaleza- no es más que el producto de un conjunto de mecanismos discursivos que - con el paso de los años- quedan sedimentados como 
verdades objetivas incuestionables, ocultando el carácter político y construido de la dimensión ontológica del sujeto.

Según explica Preciado, en el ámbito médico y psicológico del (hetero) patriarcado, el dildo cumple una función estrictamente terapéutica, ya que se utiliza cuando el orden de la naturaleza falla, como un mecanismo de compensación que se esfuerza por aliviar la angustia y el dolor que produce la dimensión de la falta. En este contexto, a través de una lógica de imitación fiel y rigurosa, el dildo se convierte en un simple sustituto artificial del pene, con el fin de preservar el contrato heterosexual del sistema capitalista, incluso cuando el órgano vivo se deteriora y deja de funcionar. ${ }^{5}$ En cambio, para Preciado, el dildo - extraño a la naturaleza y producto de la tecnología- ocupa una posición intermedia, ya que su carácter plástico y transferible se vincula con la figura del falo-significante y, a su vez, su estatuto material se acerca a la figura del pene-órgano: es una máquina-ajena a la función del consolador-, que no puede representar la naturaleza más que transformando su investidura original. Por eso, al romper la equivalencia del dildo y el pene, Preciado afirma que la plasticidad prostética del dildo es susceptible de ser representada por medio de otros significantes corporales, en un desplazamiento metonímico que desestructura las funciones orgánicas del cuerpo. El dildo, por lo tanto, ya no viene a recubrir - de manera fantasmática- ninguna falta o discapacidad anatómica, sino que garantiza una nueva reordenación de la arquitectura corporal, al margen del imperativo categórico del falo lacaniano, desarticulando la hegemonía del discurso (hetero)normativo y patriarcal. En este sentido, dice Preciado, «Si el pene es a la sexualidad lo que dios es a la naturaleza, el dildo hace efectiva, en el dominio de la relación sexual, la muerte de dios anunciada por Nietzsche» (2000, p. 68). Así, influenciada por la deconstrucción derridiana, Preciado llega a la conclusión de que el dildo es un suplemento prostético, que no hace más que recordar el carácter artificial del pene -«un sexo de mentira» (2000, p. 73), en palabras de Preciado-, anunciando el nacimiento de una nueva era

5 Para Preciado, los movimientos feministas radicales que rechazan el dildo comparten la misma retórica que los discursos médicos del sistema (hetero) patriarcal, ya que confunden el dildo con el pene. Dice Preciado: «La teoría lésbica separatista que critica la utilización del dildo, por su complicidad con los signos de la dominación masculina, cree todavía en la realidad del pene como sexo. En esta erótica hiperfeminizante, la ausencia que estructura el cuerpo, fiel a un esquema corporal monocéntrico y totalizante, guarda luto a la huella del mismo sistema falocéntrico que critica. La falta como ausencia del significante, como vacío efectivo (nunca un pene, nunca un dildo), se transforma aquí en un nuevo centro del placer (...). Estas teorías corren el riesgo de reestructurar el cuerpo a partir de otro centro vacío, cuando podrían negar el centro como centro, multiplicándolo hasta que la noción misma de centro ya no tuviese sentido» $(2000$, p. 73 y 74$)$. 
contra-sexual, más allá del orden natural del cuerpo. De esta manera, gracias a la insolencia del dildo -en donde se inscribe la muerte del pene-, Preciado desenmascara el dispositivo de la sexualidad como ideología:

Si el dildo es disruptivo, no lo es porque permita a la lesbiana entrar en el paraíso del falo, sino porque muestra que la masculinidad está, tanto como la feminidad, sujeta a las tecnologías sociales y políticas de construcción y de control. El dildo es el primer indicador de la plasticidad sexual del cuerpo y de la posible modificación prostética de su contorno. Quizás el dildo esté indicando que los órganos que interpretamos como naturales (masculinos o femeninos) han sufrido ya un proceso semejante de transformación plástica (2000, p. 67).

Así, a través de la estrategia contra-sexual del dildo, Preciado demuestra que las categorías de lo masculino y lo femenino son construcciones políticas, configuradas con el fin de preservar la lógica económica de la sociedad capitalista, a partir de la centralidad que se confiere al pene, como órgano de significación del poder en el marco del sistema (hetero)normativo y patriarcal. Sin embargo, para Preciado, el hecho de extraer del cuerpo -en forma de dildo- el órgano genital que instituye la diferencia de los sexos, se convierte en un acto subversivo -marcadamente político-, que permite deconstruir la dicotomía (¿natural?) de los cuerpos, en busca de una resexualización polimorfa de la totalidad del cuerpo. Así, en contra de la identificación de los órganos reproductivos como órganos sexuales, el dildo supone un desplazamiento del placer hacia la exterioridad del cuerpo, demostrando que el contexto de la sexualidad -al margen de la propiedad y la pertenencia- está más allá de la dimensión orgánica. En esta línea, pregunta Preciado, «¿Dónde se encuentra el sexo de un cuerpo que lleva un dildo? En sí, el dildo: ¿es un atributo femenino o masculino? ¿Dónde transcurre el goce cuando se folla con un dildo?» (2000, p. 59). Ahora, para Preciado, el dildo es lo extranjero, lo impropio, el lugar de lo abyecto: marca un placer ilegítimo, que ya no pertenece a la dimensión del cuerpo. Así, si la disposición anatómica del cuerpo biológico está ordenada jerárquicamente -privilegiando los órganos sexuales, como lugares de la (re) producción-, el dildo deconstruye la jerarquía, produciendo un placer intensivo que se distribuye de manera anárquica por todo el cuerpo. De esta manera, gracias a la estrategia del dildo, el cuerpo se convierte en una superficie horizontal (y no ya vertical), en donde los principales órganos sexuales -de acuerdo con la teoría de Deleuze y Guattari (1972) - son desterritorializados, perdiendo su función orgánica, en busca de un placer polimorfo que destruye la economía del cuerpo. ${ }^{6}$ Al final, a través de la reivindicación de la era dildotectónica,

6 A partir del programa radiofónico de Artaud, Para acabar de una vez con el juicio de Dios (1948), Deleuze y Guattari extraen el concepto de cuerpo sin órganos, 
Preciado - en contra de la performance de género butleriana- afirma que no se trata de construir un espacio imaginario para un deseo disidente -en oposición a la dimensión real del sexo-, sino que se trata de rearticular una nueva arquitectura corporal, al margen de la lógica hamletiana del falo lacaniano, en busca de una erotización alternativa de la totalidad del cuerpo.

\section{LA DESARTICULACIÓN DE LA DIMENSIÓN SIMBÓLICA: ¿UN NUEVO ESTATUTO DE LO POLÍTICO?}

Decís que la sociedad debe integrar a los homosexuales. Yo digo que los homosexuales debemos desintegrar la sociedad.

Françoise d'Eaubonne

A principios del siglo XX, la teoría psicoanalítica freudo-lacaniana se acerca a la dimensión que inaugura el cuerpo de la mujer, con el fin de comprender el funcionamiento de la sexualidad femenina. Sin embargo, a partir de la lógica hamletiana del significante fálico, el psicoanálisis lacaniano reserva el segundo término del juego dialéctico a la figura de la mujer, que se convierte en el doble especular que sustenta la dominación masculina. En este contexto, Butler y Preciado - en contra de la identidad sustantiva-reivindican la estrategia contra-sexual del falo lesbiano, con el fin de cuestionar la gramática (hetero) normativa del sistema capitalista, en busca de la construcción de nuevas subjetividades políticas. Ya no se trata, por lo tanto, de sustituir viejos términos o de incorporar el conjunto de sexualidades periféricas al sistema de la norma, sino que la estrategia consiste en modificar - una y otra vez (y sin cesar)- las posiciones de enunciación hegemónicas, como marco de posibilidad del estatuto de lo político. Al fin y al cabo, según dice Butler, «la introducción de la sexualidad en el terreno de lo simbólico cambiará muy poco las cosas si en el transcurso de esa admisión no se altera radicalmente lo simbólico mismo. En realidad, la legitimación de la homosexualidad tendrá que resistir la fuerza de la

para hablar de un cuerpo desterritorializado. Así, en El Anti-Edipo: capitalismo y esquizofrenia (1972), Deleuze y Guattari explican que el cuerpo sin órganos no es un cuerpo vacío, desprovisto de órganos, sino un cuerpo que se opone a la disposición de los órganos en el sistema orgánico, en donde cada uno de ellos ocupa un lugar preciso y cumple una función determinada. En este sentido, para Deleuze y Guattari, el organismo no es más que un estrato del cuerpo: un fenómeno de acumulación, coagulación y sedimentación, que impone una serie de formas y funciones al cuerpo, con el único fin de extraer de él un trabajo útil y (re)productivo, acorde con las exigencias del sistema capitalista. 
normalización para lograr una resignificación anticonvencional de lo simbólico que permita expandir y alternar la normatividad de sus términos» (1993, p. 167).

\section{REFERENCIAS BIBLIOGRÁFICAS}

BROWN, N. 1959: Eros y Tánatos: El sentido psicoanalítico de la historia, tr. F. Perujo. Barcelona: Ediciones de Belloch, 2007.

BUTLER, J. 1993: Cuerpos que importan. Sobre los límites materiales y discursivos del sexo, tr. A. Bixio. Buenos Aires: Ediciones Paidós, 2002.

BUTLER, J. 1999: El género en disputa. El feminismo y la subversión de la identidad, tr. Ma . Muñoz. Barcelona: Ediciones Paidós, 2007.

DELEUZE, G. Y GUATTARI, F. 1972: El Anti-Edipo. Capitalismo y esquizofrenia, tr. F. Monge. Barcelona: Ediciones Paidós Ibérica, 1985.

FREUD, S. 1905: «Tres ensayos sobre teoría sexual», en Tres ensayos sobre teoría sexual, tr. L. López-Ballesteros y de Torres. Madrid: Alianza Editorial, 2008, pp. 7-114.

____ 1923: «La organización genital infantil (una interpretación en la teoría de la sexualidad)», en Obras completas XIX. El yo y el ello y otras obras (1923-1925), tr. J.L. Etcheverry. Buenos Aires: Amorrortu Editores, 2003, pp. 141-149.

HEGEL, F. 1807: Fenomenología del espíritu, tr. M.J. Redondo. Valencia: Pre-Textos, 2009.

IRIGARAY, L. 1977: Ese sexo que no es uno, tr. R. Sánchez Cedillo. Madrid: Ediciones Akal, 2009.

KOJÈVE, A. 1937-1938: La dialéctica del amo y del esclavo en Hegel, tr. J.J. Sebreli. Buenos Aires: Editorial de la Pléyade, 1975.

LACAN, J. 1948: «La agresividad en psicoanálisis», en Escritos I, tr. T. Segovia. Buenos Aires: Siglo Veintiuno Editores, 2010, pp. 107-127. , 1949: «El estadio del espejo como formador de la función del yo [je] tal como se nos revela en la experiencia psicoanalítica», en Escritos I, tr. T. Segovia. Buenos Aires: Siglo Veintiuno Editores, 2010, pp. 81-105. - 1958: «La significación del falo», en Escritos II, tr. T. Segovia. Buenos Aires: Siglo Veintiuno Editores, 2010, pp. 653-662.

1972-1973: Seminario XX: Aún, Buenos Aires: Editorial Paidós, 1989. 
PRECIADO, P. B. 2000: Manifiesto contrasexual, tr. J. Díaz y C. Meloni. Barcelona: Editorial Anagrama, 2011.

WITTIG, M. (1992): El pensamiento heterosexual y otros ensayos, tr. J. Sáez y P. Vidarte. Barcelona: Editorial Egales, 2012.

ZIZEK, S. 1989: El sublime objeto de la ideología, tr. I. Vericat. Madrid: Siglo XXI Editores, 2010.

Maider Tornos Urzainki, Pamplona, 1982

Publicaciones:

1. «El cuerpo está aparte: autobiografía(s) en Marina Abramovic, Francesca Woodman y Ana Mendieta» (escrito con Ester Pino Estivill). En María Teresa Vera Rojas (ed.), Nuevas Subjetividades/Sexualidades Literarias, Barcelona, Editorial Egales, 2012, pp. 149-172. ISBN 978-84-15574-72-9.

2. «Del topo a la serpiente: la transformación de la pulsión lacaniana en la sociedad posthumana de los cuerpos virtuales» en Caracteres. Estudios críticos y culturales de la esfera digital, 3-1, Mayo de 2014, pp. 168-178. ISSNe 2254-4496 [en línea]: revistacaracteres.net/wp-content/uploads/2014/05/Caracteresvol3n1mayo2014pulsion-lacaniana-sociedad-posthumana.pdf

3. «Los límites del discurso: estudio sobre Histoire de l'CEil de Georges Bataille». En Anuario de Estudios Filológicos, XXXVII, 2014, pp. 269-284. ISSN 0210-8178.

4. «Del goce lacaniano a la escritura femenina: la histerización de la palabra en Hélène Cixous». En Lectora: Revista de Dones i Textualitat, 20, 2014, pp. 175-190. ISSN 1136-5781.

Líneas de investigación:

Teoría y crítica literaria, psicoanálisis, estudios de género y teoría queer.

Correo electrónico: argazkia@yahoo.es 
